Meta

Journal des tradlucteurs

Translators' Journal

\title{
On Translating the Mental Status Schedule
}

\section{Irène V. Spilka}

Volume 13, numéro 1, mars 1968

URI : https://id.erudit.org/iderudit/004235ar

DOI : https://doi.org/10.7202/004235ar

Aller au sommaire du numéro

Éditeur(s)

Les Presses de l'Université de Montréal

ISSN

0026-0452 (imprimé)

1492-1421 (numérique)

Découvrir la revue

Citer cet article

Spilka, I. V. (1968). On Translating the Mental Status Schedule. Meta, 13(1), 4-20. https://doi.org/10.7202/004235ar d'utilisation que vous pouvez consulter en ligne.

https://apropos.erudit.org/fr/usagers/politique-dutilisation/ 


\section{ON}

\section{TRANSLATING}

\section{THE MENTAL STATUS SCHEDULE *}

The translation of psychiatric research instruments presents special problems because it must combine the precision, accuracy and clarity required of technical translations with the equivalence of effect and ease of readability expected of literary translations. Typically, the original text consists of questions or statements striving to imitate the casual, non-specific language of the man in the street, yet related to precise scientific concepts and specific clinical entities; the subjects used in psychiatric research are not sophisticated and cannot be expected to make allowances for strange or unusual expressions resulting from awkward translating; most important of all, any modification of the original instrument occurring in the process of translating invalidates findings based on a comparison of responses in two languages. In comparing answers obtained on translated English and French questionnaires, Prince and Mombour noted that «...even when a reasonable degree of care is taken in translating a simple instrument into French, a considerable discrepancy in meaning exists between the two versions $»^{1}$, and suggested a validation procedure which may be applied before translated instruments are employed in cross-cultural research. The object of this article is to examine the problems encountered in translating the Mental Status Schedule (MSS) from English into French, and to describe the techniques employed in solving them.

The MSS is described by the author as

....an instrument designed to improve the research value of clinical judgments of psychopathology based on data collected during a psychiatric interview of a subject.

...the instrument is a booklet which contains both a standardized interview schedule and a matching inventory of 248 precoded items. The interviewer uses the interview schedule to elicit information needed to judge the items

* Robert L. Spitzer, Eugene I. Burdock and Anne S. Hardesty, The Mental Status Schedule, Biometrics Research, N.Y. State Department of Mental Hygiene; Research Division, Washington Heights Service, N.Y. State Psychiatric Institute; Department of Psychiatry, Columbia University, 1966.

1. Raymond Prince and Werner Mombour, "A Technique for Improving Equivalence in Cross-Cultural Surveys $»$, Mimeographed paper, Montreal, 1966. 
of the inventory. The focus is on interview behavior and symptoms occurring during the past week.

...the interview schedule provides for a material progression of topics and consists of a series of statements and predominently open-ended questions. Supplementary questions are provided to clarify or probe areas when the interviewer needs more information to make a judgment. The interviewer records his judgments on a score sheet as the interview progresses...

This description is not complete without an account of the language used. It is not sufficient to say that a text is written in English, for, as Catford states:

The concept of a «whole language » is so vast and heterogeneous that it is not operationally useful for many linguistic purposes, descriptive, comparative and pedagogical. It is, therefore, desirable to have a framework of categories for the classification of «sub-languages 》 or varieties within a total language; that is, idiolects, dialects, registers, styles and modes. ${ }^{2}$

The variety of English used in the MSS is American English spoken by white middle class people in large Eastern cities. Two examples should suffice to illustrate this point: the expression « wishful thinking » is used as a synonym for «daydreaming »; in British and Canadian usage, «wishful thinking 》 applies to a statement clearly reflecting an unconscious wish of the speaker, e.g., « John will get sick before the race (while in reality John is in perfect health but Joe would like to see him get sick in order to eliminate a dangerous rival from the competition). Another example is the predominance of nominal constructions where British usage would have preferred verbal construction, e.g., " (he is bothered by) feelings of guilt » for « he feels guilty (and it bothers him) 》.

Another relevant feature of language is register which Catford defines as a « variety related to the wider social role played by the performer at the moment of utterance, e.g. «scientific $»$, * religious , « civil-service», etc. ${ }^{3}$. The MSS makes use of two registers, one in which the interviewer speaks as « doctor-topatient» (in the interview schedule) and another as «interviewer-to-colleagues 》 (in the inventory). Register markers are mostly lexical and grammatical. In the schedule, we encounter a large number of colloquial terms, e.g., «bother » for « annoy », «weird ₹for " queer », and constructions, e.g., «Whom do you feel you can trust the most?». The inventory, on the other hand, is marked by the use of technical and semi-technical terms, e.g., "/phobia/», « irrational fears » (compared to «fears they know don't make sense » in the matching question). A grammatical feature of the scientific register is impersonality reflected in the low frequency of personal pronouns « $\mathbf{I}$, you, she, he $»$; the inventory uses only «he 》 and does so in an impersonal way by using it in reference to patients of either sex.

The mode is "the medium in which the performer is operating ${ }^{4}$. In this case, the schedule was prepared in the spoken mode; sentences are short, constructions simple, and long or unusual words absent; subordinating conjonctions are kept to a minimum, voice modulation being sufficient to indicate connections. The inventory is in the written mode, sub-style abbreviated (but not quite

2. J.C. Catford, A Linguistic Theory of Translation. An Essay in Applied Linguistics, London, Oxford University Press, 1965.

3. Ibid.

4. Ibid. 
《telegraphese $»$ ), e.g., the pronoun is invariably omitted before the first verb: « Refuses to shake hands. »

Style is a language variety \&...related to the number and nature of addressees and the performer's relation to them... $\gg^{5}$ It is of particular interest to the translator who strives to achieve equivalence of effect. Joos recognizes five styles for English, these are frozen, formal, consultative, casual and intimate. His definitions of casual and consultative styles are particularly relevant to the MSS schedule:

The two defining features of consultative style are:

1) The speaker supplies background information.

2) The addressee participates continuously.

Because of these two features, consultative style is our norm for coming to terms with strangers - people who speak our language but whose personal stock of information may be different.

But treating the listener as a stranger is hard work in the long run; therefore we sooner or later try to form a social group with him. Our most powerful device for accomplishing this is the use of casual style. ${ }^{6}$

On the positive side of casual style, Joos mentions ellipsis and slang which he considers as a widely used but ephemeral language designed to include the addressee and exclude outsiders, a somewhat more comprehensive definition than is generally given by dictionaries.

Consultative and casual styles are both used in the schedule and the smooth transition from one to the other contributes to the flowing and «natural » quality of the text. Information is given and requested directly, e.g., "When a person feels depressed or hopeless, he may think about his own death. Do you ? , and consultative markers, e.g., "how often, what kind 》 are numerous. But ellipsis also occurs, e.g., "What about feeling restless? » and slang (as defined by Joos) is frequent, e.g., «blue » for « low-spirited », « high » for « elated ».

The inventory, on the other hand, is not designed for active participation by addressees. The interviewer merely checks off the items most closely corresponding to the patient's answers and forwards the completed score sheets to his associates. This is reflected in the use of formal style. Formal markers are lexical, e.g., « unduly» which might come out as « too much» in consultative style, and semantic, e.g., intended meaning is defined for the benefit of the addressee as in « Makes up new words /neologisms/».

A writer's idiolect does not always have to be translated, but it should always be looked at closely because it has a bearing on the translator's understanding of the original text. Catford defines it as

...the language variety used by a particular individual. The markers of an idiolect may include idiosyncratic statistical features, such as a tendency to exceptionally frequent use of particular lexical items. ${ }^{7}$

A pronounced «idiosyncratic statistical feature $»$ of Spitzer et al. is the use of paired synonyms, e.g., «problems or difficulties», « depressed or blue », « to kill yourself or commit suicide $»$. Paired synonyms are a traditional feature of

5. J.C. Catford, op, cit.

6. Martin Joos, The Five Clocks, Indiana University Research Center in Anthropology, Folklore, and Linguistics Publication Twenty Two; also Part V of the International Journal of American Linguistics, Vol. 28, No. 2 (1962), The Hague, Mouton, 1962.

7. J.C. Catford, op. cit. 
English and can be found in archaic expressions such as the legal injunction to «cease and desist» as well as in modern phrases such as the airlines' favorite «for your comfort and convenience»; what makes them worth noticing in the MSS is their high frequency and their nonce quality. Whereas "to cease and desist », «to aid and abet » are frozen idioms belonging to the language of law, it is not so in the case of «problems or difficulties », "blue or depressed 》, 《to kill yourself or commit suicide» which are idiocratic expressions, peculiar to the MSS and not frequently encountered elsewhere.

Definitions of translating are perhaps as numerous and varied as the authors who have undertaken to discuss the subject. Catford, whose approach to translation may well be the most scientific one to date, states: «Translation may be defined as follows: The replacement of textual material in one language (SL) by equivalent textual material in another language (TL).» 8 This calls for elaboration. Replacement may be full or partial according to the extent to which it is carried out, that is according to how much material is subjected to the translation process; it may be total or restricted depending on the level at which it takes place (phonological-graphological, grammatical-lexical); an example of phonological translation is found in the "foreign accents 》 assumed by actors impersonating foreigners; and it may be rank-bound (as when only word-to-word equivalences are sought) or unbounded (as when equivalences occur between higher rank units such as sentences). According to these categories, the translation of the MSS is full, restricted and unbounded.

Equivalence is related to the aims of translation; formal equivalence is source-oriented, that is « designed to reveal as much as possible of the form and content of the original message ${ }^{9}$; its aim is to achieve concordance of terminology with the original text. Dynamic equivalence is concerned with receptor response and can be described as "the closest natural equivalent to the sourcelanguage message $\gg{ }^{10}$; in Nida's words, it should cause a bilingual and bicultural person to say: "That is just the way we would say it. ${ }^{11}$ Dynamic equivalence was sought throughout the translation of the MSS.

Although no formal yardstick has yet been devised to gauge translations, quality in translation is considered to be a function of 1) accuracy of content, 2) elegance of form, and 3) similarity of response (see the results of Cary's survey ${ }^{12}$ ). Understandably, accuracy is the first requirement to be stressed by literary and scientific translators alike. Yet it is sometimes far more difficult to achieve than, let us say, elegance of form. As Kandler put it:

translating is the effort of rebuilding a similar texture of thought by means of another language, i.e. by means of another set of symbols, different not only in the form of each lexical and syntactic unit, but rather - which is much more important - in the «meanings $»$ of all those units. ${ }^{13}$

8. J.C. Catford, op. cit.

9. Eugene A. Nida, Toward a Science of Translating, with Special Reference to Principles and Procedures Involved in Bible Translating, Leiden, E.J. Brill, 1964.

10. Eugene A. Nida, op. cit.

11. Ibid.

12. Edmond Cary and R.W. Jumpelt, ed., Quality in Translation, Proceedings of the International Federation of Translators (FIT), Bad Godesberg, 1959, Oxford, London, New York, Paris, 1963.

13. Ibid.

Vol. $13-\mathrm{N}^{\circ} 1$

Mars 1968 
The question of meaning is central in translation and will be taken up in detail later in this article.

Concern over elegance of form is not limited to literary translation. As translators understand it, it refers not only to the refined grace and richness of expression of literary prose, but to an esthetic aspect of language which is essential in all communication, it is a combination of clarity with ease of expression in order to produce the kind of fluency which makes understanding easier. Jumpelt, in his introduction to the symposium on scientific and technical translation held during the Third Congress of the FIT, made this clear; after stressing the importance of exact terminology in translating scientific material, he focused on the «other dimensions »:

This much appears certain: in scientific texts the essential information (message) is not exclusively or explicitely carried by terms but, on the contrary, is conditioned by semantic features of the common language such as are implicit in certain word-classes, grammatical categories, syntactical patterns and combinations thereof - indeed, in all features of language.

It would seem, then, to be the interaction between these elements, including technical terms but not these alone, that the translator must scan for their relevance to the message and its purport. ${ }^{14}$

Similarity of response, that is comparable reactions by the audience to the original and the translation, may well be the aspect of translation of greatest concern to the social sciences. It is precisely what Prince and Mombour ${ }^{15}$ had in mind when they suggested validating translated material before the start of an experiment, in order to determine which variations in response are due to the experimental situation and which are ascribable to the translation. While we agree with Kandler that «an ideal translation would be one that allows for exactly the same breadth of interpretation (and even misinterpretation) as the original ${ }^{16}$, we know that it is often impossible to render all the dimensions of the original, particularly the affective and emotional values ascribed to words along with their intellectual or ideational content, for the reason that concepts, affects and words are associated differently in different languages. This question will be taken up again in the discussion of meaning.

The components of translation are 1) the text, 2) the translator, 3) the audience, and 4) the source and target languages. A text can be described as a string of linguistic elements arranged in accordance with 1) the rules of a particular language and 2) the author's intent. Language rules are binding (one cannot use «hte for «the », «two man » for «two men», «I when him saw » for "when I saw him»), they concern the choice of elements and their arrangement, and they constitute the grammar of a language or what Vinay and Darbelnet call «servitudes ${ }^{17}$ in contrast to options» or choices afforded by the possibility of choosing from among many permissible utterances. As a result of this possibility, a given text occupies only a restricted area within the whole language, which is defined by spatial (dialect proper), temporal (état de langue), social

14. Edmond Cary and R.W. Jumpelt, op. cit.

15. Raymond Prince and Werner Mombour, op. cit.

16. Edmond Cary and R.W. Jumpelt, op. cit.

17. J.-P. Vinay and J. Darbelnet, Stylistique comparée du français et de langlais, Paris, Didier, et Montréal, Beauchemin, 1958. 
(social dialect) and other characteristics. We have already described the overall linguistic characteristics of the MSS.

Since a text is a string of elements, it follows that position is a relevant feature, e.g., a word's meaning may be affected by the items surrounding it; these are called the co-text. Elements outside the text, that is the situation within which it occurs, may also be linguistically relevant; these constitute the context.

Among the various kinds of contexts, such as times, place, social position, etc., the broad cultural context of a given text must be examined. An understanding of it is needed to determine the meaning of the original utterance because words refer to things and things exist in relation to other things in a total cultural setting. Does « to kill yourself » mean the same thing in the U.S. and in Japan? Conversely, the cultural context of the target language determines the choice of terms in the translation: which item of culture B corresponds most nearly to a given item in culture $\mathrm{A}$ and what is it called? A case in point is the use of «hopital» and «clinique » in France and in Canada; whereas in France the first refers to a public institution and the second to a private establishment, exactly the reverse is true in Canada, but then again the organization of medical facilities is quite different in the two countries, so that even when we match the words to the general characteristics of the thing referred to, we only approximate the meaning of the original text. We will have more to say on this subject in our discussion of meaning.

This brings us naturally to the question of audience. It is necessary to know who will be using the translation and whether or not the users will form a homogeneous group. In the case of the MSS, which was originally designed for American audiences, two target-groups were kept in mind: French and FrenchCanadians. It is well known that cultural and linguistic differences characterize these two groups. French-Canadians, because of their proximity to the United States are in many ways acculturated to the American way of life; they are neither surprised nor offended, for instance, by the use of tests and standardized interviews, while in France these techniques often meet with suspicion and resistance because they are regarded as an invasion of privacy. One item in the MSS directly affected by this kind of differences is the following question: "What kind of thoughts do you have that other people wouldn't understand? ». While the need to conform may not be stressed to exactly the same degree in FrenchCanada and in the United States, French-Canadians are much more willing to recognize a desire for conformity within themselves and to admit to some anxiety about «feeling different 》 than the French, who feel it behooves them to be unique, and are therefore reluctant to admit that they don't have ideas that others would not understand. Two translations had to be provided for this particular question in order to enable subjects in each group to answer meaningfully: «Avez-vous des pensées que les autres ne comprendraient pas?» seems more acceptable to the French than "Avez-vous des idées que les autres n'ont pas?» (which suggests an enthusiastic «yes», meaning "I'm full of original ideas ! ). French-Canadians, on the other hand, tend to answer the first question with complaints about members of the family who are unsympathetic to the expression of a legitimate desire (to marry, for instance) of the patient's, while they readily 
interpret the second question in the sense intended by the author.

In addition to cultural differences, French and French-Canadian audiences exhibit linguistic differences which are not always recognized or well understood. The most obvious feature of language to a layman is the speaker's « accent 》 (i.e., peculiar way of articulating the sounds of his language). Yet pronunciation alone does not affect meaning. Frenchmen from Toulouse and Brest have different «accents » yet they attach much the same general meanings to words while many French-Canadians who have succeeded, by dint of «corrective exercises », in achieving a «standard» pronunciation continue to evoke French-Canadian concepts when uttering French words. The term «ami» certainly covers a much wider range of persons in French-Canada than in France, regardless of how it is pronounced.

What complicates matters further is the fact that doctors and patients do not share the same background in this respect. The patient, especially in public wards, is likely to stay close to home in matters of language. Because his education probably did not extend beyond high school, he has not been in close and prolonged contact with international French, which is mostly taught in «collèges » through the study of classical literature, nor, for that matter, with English other than the everyday business variety which has trickled down to him through commercial advertisements. The doctor, on the other hand, has received a "classical education $\gg$ stressing the study of 17 th, 18th and 19th century French literature. He is aware that differences exist between his home tongue and the international variety and he may even have adopted the latter as a matter of personal choice (not a few French-Canadian psychoanalysts have been analyzed in France; these are as close to their French colleagues as to their FrenchCanadian patients). In addition, the French-Canadian doctor is as likely as not to have received his post-graduate training in the U.S. - in any case a large percentage of his textbooks were written in English. He is therefore at home with American concepts and expressions. This became evident while discussing the MSS with French-Canadian psychiatrists who frequently expressed the opinion that, compared to the French translation under consideration, the American phrase or word was «so much more expressive, more meaningful » (a somewhat comical assertion, since for a monolingual French-speaking patient it would have been totally meaningless).

An important linguistic difference between educated French-Canadians and their French counterparts affects items in the inventory, which are meant for doctors and other highly educated specialists. The French shows a marked preference for so-called «abstract» (i.e., more general) terms in contrast with American and French-Canadian predilection for «concrete» (i.e., more specific) expressions. For example, «Clothes are dirty and in disarray » would normally be translated in France (in formal style) by «Tenue vestimentaire négligée 》 but Canadians preferred «Porte des vêtements sales ou en désordre». A compromise solution was to drop the verb and keep "Vêtements sales ou bien en désordre " which gives the statement the appearance of being concise, since it is short, yet preserves the distinction between «dirty» («sales») and «in disarray» («en désordre 》) which would be lost in using «négligée» alone. This is a small 
concession to international French preference since the real issue was «tenue vestimentaire 》 vs. "vêtements»; unfortunately "tenue vestimentaire»" does not lend itself to syntagmatic arrangements with «sales» and «en désordre » which are key words in this case.

This whole issue bears on the question of similarity of response. When an interviewer is presented with an item coded in terms to which he is unaccustomed (i.e., too «abstract» or too « concrete», too «familiar» or too «formal », etc.) he is likely to stop and ponder its meaning rather than respond to it spontaneously - and since he is looking for a hidden meaning he is likely to find one where none was intended - with the result that his response will be more deliberate and calculated, and probably slanted in the direction of his pondering. This difference between French-Canadian and standard or international French usages was a serious problem in translating the inventory; it was finally resolved by finding a compromise solution for each case, but the compromise could not, as a rule be effected exactly half-way between the two positions. Because it was felt that Canadians are more tolerant of French tradition than French doctors would be of French-Canadian divergence, and because the probability that FrenchCanadian doctors understand both Canadian and international French is greater than that French doctors understand Canadian dialect, the meeting point was located somewhere between two-thirds and three-fourths of the way toward the French position.

The translator may be a person working alone, a team working together or in succession, or a committee. Since translation by one person risks introducing bias, revision by a committee is considered desirable whenever possible. In the present case, a draft was prepared by the author of this report (after two previous drafts had been considered inadequate, one prepared by a commercial translator, the other by a bilingual psychiatrist untrained in translating); this was submitted to a committee composed of bilingual psychiatrists of French-Canadian and Anglo-Saxon origin, practicing in French and English language hospitals of the city; a visiting psychiatrist from France was later consulted separately. Each question and corresponding item was read to the committee in English and in French, and comments were invited concerning the meaning of the original text and the proposed translation; the ensuing debates were recorded on tape for further reviewing. When the original meaning could not be elucidated to the committee's satisfaction, the author was called in for consultation. After a revised draft had been completed, it was presented to patients and their reactions were noted by the interviewing psychologist for more discussion and revision by the committee until it was felt that no further improvements could be made by this method.

Languages are, among other things, patterns used in communicating. They differ from one another in the selection of their basic elements (compare the phonemes of English and French) and in the way these elements combine (e.g., English places modifiers before the term modified while French places them after: "he is easily upset», "il se trouble facilement»). Languages also differ in what they communicate, that is not so much in what they can communicate as in what they must communicate. An example of this frequently recurring in 
the MSS is the interrogative form «How often ...»; although « how» is translated by «combien» and « often » by «souvent», the combination «combien souvent» is not permissible. In order to find out how often something occurs, French speakers must either ask «Cela vous arrive-t-il souvent? 》 or "Combien de fois par semaine, par jour, etc., cela vous arrive-t-il?» The first form is vague like the English one, but unlike its English counterpart it is likely to draw a yes or no answer; in order to obtain a numerical answer, the second form should be used, but this is more specific than the English form inasmuch as is set a time limit to the addressee. Another example is English «impotent» which does not distinguish between inability to get an erection and inability to expel semen (unless, of course, an adjective is added as in «erective impotence $»$ and « ejaculatory impotence 》) but French must choose between «impotent 》 and «impuissant » thus making the target-text more specific than the original. In translating, problems arise whenever the source language is less specific than the target, since additional information is required to find the proper equivalence. In such a case, the author may be consulted or outside clues used; when this is not feasible, it may be necessary to list the various possibilities contained in the original. On the other hand, when the source language is more specific than the target language, a «loss of meaning $»$ occurs unless the translator is careful to narrow down the field of the corresponding target item. One question was originally worded: «Mentions he loves himself ... ». In contrast to English «love» vs. «like», French has only «aimer » relying on co-text or context to make the difference clear. As every girl knows «Je vous aime» means «I love you 》 but «Je vous aime bien $»$ is merely «I like you . To make up for the loss of specificity in French, in this case, a sentence had to be added: "Dit qu'il a une excellente opinion de lui-même. »It is interesting to note that when the English version was reworked, the new wording came very close to our own rendition: «In appraising himself he indicates an inflated view of his value or worth. $\gg$

Languages are to some extent culture bound. This is most evident in the content of the lexicon; obviously a pre-industrial culture has no words pertaining to machines as we know them, to take but one example. Much has been made of this as it affects the translation of names of colors and terms referring to different types of family structure. Clearly this is a serious problem and one which can only be solved by extensive comparative cultural studies prior to translating, and by expanding the target text sufficiently to explain what is meant in the source text. In the case of colors, for instance, a solution may be found in making use of comparisons involving natural phenomena, e.g., the color of the sky, the color of the grass, etc. Gross differences of this kind are not common between English and French, although «brown paper» does come out as «papier gris» 18 , but more subtle ones may be present in pairs such as «tired/fatigué », where quantitative difference is suspected, and «guilt/culpabilité » where qualitative divergence is expected.

As can be inferred from the preceding remarks, the bulk of the translator's work consists in finding ways and means of achieving equivalence as defined above. For this he has at his disposal a standard procedure and a set of techniques.

18. J.-P. Vinay and J. Darbelnet, op. cit. 
Procedure refers to the steps taken in performing his work, and techniques to means of solving problems.

Techniques and procedures

The first step (really a part of his training) consists in mastering both the source and target languages in which he is going to work. In the present case, this involves the following:

1) Practical competence in English and French, that is a command of both languages sufficient to ensure complete understanding of all the lexical and syntactic structures included in the English text together with the ability to produce comparable written French prose.

2) Formal training in linguistic analysis and translating techniques; while a bilingual person can understand and spontaneously generate sentences in two different languages, formal training is required to ensure proper matching of equivalent sentences originating in two languages. Untrained bilinguals and polyglots are constant victims of linguistic interference (e.g., matching form to form regardless of meaning; breaking through of the mother tongue into the foreign language and vice versa; contamination of semantic areas, etc.). It was the lack of this training which caused the failure of the bilingual psychiatrist's translation.

3) Familiarity with the subject matter, in this case psychiatric language and thought. This implies more than a mere knowledge of technical terms (we have already noted that the MSS includes only a few terms of this nature) requiring an actual grasp of the subject. Comprehensive knowledge of all areas of psychiatry cannot be expected of the translator unless a psychiatrist-translator is employed (and psychiatrists are otherwise occupied) but an understanding of psychiatric concepts can be achieved by reading and discussion. It was the absence of this feature which caused the failure of the commercial translator's version.

The second step consists in correctly interpreting the original text, in other words, in gaining full understanding of its meaning. Meaning is a much discussed topic, and approaches to it vary with the disciplines attempting to analyze it. Philosophers concerned with questions of truth and reality may look for it in the relationships between signs, referents and language users; psychologists interested in human behavior, may find it in the manifest changes occurring within organisms in response to verbal stimulation; linguists, focussing on language as form, have traditionally shield away from the study of meaning, being content to describe it briefly as a "relation between name and sense ${ }^{19}$. For the translator meaning is crucial, and pressed by the need to produce a text, he must effect a synthesis and arrive at a definition of his own. Nida suggests defining meaning by means of a series of contrasts which he reduces to three dimensions: «situational vs. behavioral, linguistic vs. extralinguistic, and extraorganismic vs. intraorganismic ${ }^{20}$. While we agree with Nida's contrasting approach, we find it necessary to relate linguistic meaning to a broader categorical frame organized along the following lines:

External-internal. Language items may be considered in their relations to other language items or to non-language items. In this sense, «angry » refers to

19. Stephen Ullmann, Semantics: An Introduction to the Science of Meaning, Oxford, Basil Blackwel!, 1964.

20. Eugene A. Nida, op. cit. 
a class of unpleasant affective states occasioned by the perception of offensive, painful, opposing or threatening objects. This kind of relation is often described as « referential», « extralinguistic», or «metalinguistic ${ }^{21}$. It has been argued that external meaning could not be compared from one linguistic community to another because the perception of reality was influenced and dominated by linguistic organization ${ }^{22}$. This position has more recently been modified to include the possibility that while some perceptual patterns might be influenced by linguistic patterns, others are more closely related to organic conformation and may be language free. For a philosophical discussion of external meaning in translation, we refer to Quine who recognizes the existence of what he calls «empirical meaning $\gg$ :

Empirical meaning is what remains when, given discourse together with all its stimulatory conditions, we peel away the verbiage. It is what the sentences of one language and their firm translations in a completely alien language have in common. ${ }^{23}$

For a more empirical approach, the work of anthropologist Kluckhohn is of interest. She sought to devise an instrument to measure value orientation among several language communities and her results led her to the conclusion that

there are some human problems and some generalized types of life situations which are sufficiently universal that the question of variations in languages and the variations in the thought ways of these languages express differences which are not insurmountable barriers for significant cross-cultural testing. And, it is further argued that if this be true, then there is a fairly wide range of more specific types of differences in cultures - specific differences which a «language bound» test instrument might well fail to capture directly - which can be predicted on the basis of the answers to highly general questions on the still more abstractly conceived value orientations. ${ }^{24}$ In translating, the ideal solution would be to arrive at an exact measure of external meaning differences between two cultures before matching these to linguistic items. However, this is nearly always impossible and an intuitive understanding of these differences is all that we have to rely upon.

In considering external meaning, it must be remembered that the co-text exerts an influence on any item in a sentence. Consider, for instance, " angry young men », « angry old woman », « angry sky» and « angry wound». In each case the external meaning of «angry » is determined in part by the external meaning of other items in the surrounding text.

In relation to other items in the system, « angry » may be said to belong to a subset of the word class which includes «furious, infuriated, enraged, raging, incensed, sore, mad, disturbed, troubled, irritated, exasperated, chagrined, bothered, irked, agitated, perturbed, provoked, nettled $»$. This is often called «linguistic » meaning ( $\ll$ valeur $\gg$ in Vinay and Darbelnet's ${ }^{25}$ terminology which follows de Saussures' closely).

21. J.-P. Vinay and J. Darbelnet, op. cit.

22. Benjamin Lee Whorf, Language, Thought, and Reality, selected writings, ed. with an introduction by John B. Carroll, Cambridge (Mass.), Technology Press of M.I.T., and New York, Wiley and Sons, 1956 .

23. Williard V. Quine, "Meaning and Translation ", On Translation, ed. by Reuben Brower, Harvard University Press, 1959.

24. Florence Rockwood Kluckhohn, "A Method for Eliciting Value Orientation ", Anthropological Linguistics, Vol. 2, No. 2, 1960, p. 1-23.

25. J.-P. Vinay and J. Darbelnet, op , cit. 
Internal meaning may be either lexical or syntactic. The lexical meaning of " angry », i.e., its position in relation to other items in the same class, has just been outlined above; its function in the sentence may alter its meaning. Compare "he looks angry " and «angry words »; in the first case, any one item from the list can substitute for "angry 》 (e.g., "he looks furious») but not in the second case (e.g., « furious words »).

Public-private. For communication to be possible within a speech community a minimum of agreement on the meaning of words is necessary among language users. «To feel nervous $\gg$ may have nothing to do with nerves in the neurologist's view of things, yet be quite adequate to describe a class of uneasy feelings as long as physician and patient agree on what is meant.

Words may also be used in communicating with oneself, in which case they escape public scrutiny and their meanings evolve in idiosyncratic directions. Private meanings are frequently encountered among psychiatric patients, particularly among schizophrenics.

Unlike the internal-external dimension, which is an either-or phenomenon, public-private refers to a continuum: at one extreme we have communication limited to the self (e.g., in schizophrenia) and at the other, communication between immeasurable groups, of which the Voice of America speaking to Europe, or Expo 67 are illustrations. Between these two poles there is room for groups of varying sizes. One question in the MSS which stirred up much discussion related to this dimension of meaning. One psychiatrist on the reviewing committee strongly felt that « kind of fears » would evoke what he called «fears of states of being », e.g., fears of being poor, alone, growing old, while «avoir peur» would elicit narning specific objects, e.g., cats, spiders, etc. As it turned out the problem with French-Canadian patients was somewhat different, women admitting readily to fearful states, specific fears or vague, diffused fears, while men regularly denied fear in answer to a direct question (although they revealed their fears at other points in the interview). To get around this difficulty, an introductory statement was introduced in the French version: "La plupart des gens ont des peurs》 which seemed to soften the blow sufficiently, so to speak, to enable both male and female patients to answer the relevant part of the question: "Quelle sorte de peurs avez-vous?». In other words, a direct question concerning fear or kinds of fears carries a second meaning for French-Canadian males (private meaning) namely: this question must be answered in the negative, unless a statement cancelling this meaning is introduced into the question. As for the matter of 《fears of states of being » vs. "fears of specific objects», consultation with the author ascertained that the information sought was « class of objects, experiences and situations » causing fear and that probing was generally necessary to elicit a suitable answer.

Conceptual-affective. While it is true that any emotion can be associated with any idea, and therefore any word can arouse any emotion, some language signs regularly express concepts linked with affects while others regularly designate concepts alone. Words such as "name », "memory », «town», «to look», « recently», are likely to be no more than convenient labels for concepts, while «troubles », «sex», " to die », «to accuse » are likely to arouse emotion at the 
same time that they refer to something in external reality. A good illustration of this point is found in English where words referring to bodily functions are divided into two groups: words of Latin origin which are conceptual, and words of Anglo-Saxon origin which are affective. Although some words are regularly considered affectively neutral (e.g., "table », "to salivate») and others regularly good (e.g., «to smile »), bad (e.g., four letter Anglo-Saxon words) or even. dangerous (e.g., linguistic taboos), many words can function at either end of the scale depending on co-textual and contextual influences. For example, «sex» is conceptual in the string "name, age, sex, ward » but affective on a billboard advertising "GIRLS, LOVE, SEX».

There is considerable variation among languages in the way concepts, affects. and words are associated. Compare, for example:

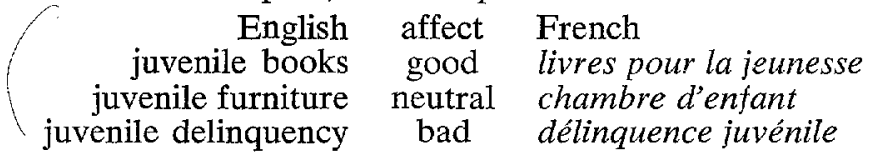

In spite of their similarity of form and intellectual content, «juvenile » and «juvénile» do not have the same affective range.

Intentional-situational. Intentional meaning is what the author of an utterance wishes to convey; it may be rendered obscure or ambiguous by his own linguistic inefficiency or by deliberate attempts at concealment. At one point in this interview the interviewer is required to note whether the patient « Keeps virtually the same posture throughout the interview $\gg$. Stated in more direct language; the intentional meaning of this item would go something like this: «Does the patient show signs of catatonia?». Being aware of this helps choose the right expression from among several possible ones in the target language. In this case, it was felt that «Se tient à peu près immobile durant toute l'entrevue » would come closest to evoking the picture of catatonic stupor without actually naming it. Another example, this time clearly stated, is found in the specific range of external meanings assigned by the author, in his set of instructions, to certain introductory verbs and phrases: «Keeps [signifies that] the behavior has occurred three or more times during the interview. $\gg$ Recognition of intentional meaning is most important to achieve accuracy. In the present case, introductory verbs and phrases had to be found for the French translation which would meet the author's requirement of constancy of use and meaning. Since, as already noted, comparable words combine differently in different languages, it was difficult to find French verbs which would match the English exactly in content and syntactic range. As a matter of fact « keeps », which is a verb, had to be translated by «constamment » which is an adverb and, as it turned out, was the only one from a set of synonymous expressions that would combine syntagmatically in all the sentences where it was required in the MSS.

Situational meaning reflects the influence of context on utterances. Asking someone about his troubles is likely to produce different responses in a bank and in a hospital regardless of the speaker's intention. Situational meaning is often strong enough to make clear an otherwise obscure, ambiguous or incomplete sentence, and conversely to interfere with the intentional meaning of a well formed sentence. 
Verbal-behavioral. Although language can be regarded as behavior, a distinction is generally made between verbal and motor activity. The appropriate response to certain linguistic stimuli is a verbal one (e.g., «Hello!», «What's your name ?») while in other cases overt behavior is called for (e.g., «Stop!», "Come out of there. »). "Please spread your fingers and do what I am doing 》 requires a behavioral response. This is indicated in English by beginning the sentence with «Please» and using a verbal imperative. French also requires a verbal imperative, but « $s^{\prime} i l$ vous plait » generally indicates a request rather than a command, unless formal politeness is intended which is not the case here.

Although they do not exhaust all the semantic possibilities of a text, these five dimensions provide a useful tool with which to interpret the meaning of the source and to measure the accuracy of the target equivalent.

Determining appropriate target language equivalents constitutes the third step in translating. Techniques of adjustment used at this point have been suggested by Nida ${ }^{26}$ who indicates three basic modes operating at the sentence level: addition, subtraction, alteration, and by Vinay and Darbelnet ${ }^{27}$ who describe seven techniques applicable to smaller units ( unités de traduction»).

Two examples of addition have already been given, one in connection with a statement of fears in which an introductory sentence had to be inserted before the actual question in the French version; the other concerning bizarre thoughts which others would not understand where alternate translations had to be supplied in accordance with the needs of two different types of audiences.

An example of subtraction (which is much less common) occurs in the following item where «Indicates he gets a strange feeling as if an experience he is having is familiar /déjà $v u / . »$ becomes «Fait comprendre qu'il éprouve une impression étrange de déjà $v u$ en présence des événements actuels. /déjà vu/. A comparison segment by segment will show what was left out and why:

English
Indicates
he gets
a strange feeling
as if
an experience
he is having
is familiar
/déjà $v u /$.

French

Fait comprendre qu'

il éprouve

une impression étrange de

... des événements ...

en présence ... actuels

déjà vu. / déjà vu/.

We see that « as if » and « is familiar » were not translated because their meaning is implied in the French « déjà $v u »$ (which was borrowed from it by English terminology to begin with). It will be noticed that « déjà $v u »$ is repeated in brackets at the end of the statement, thus saying the same thing twice. The reason for this is that throughout the MSS certain technical terms, printed in italics and enclosed in square brackets, are made to stand out after a number of items along the right hand margin. The repetition occurring in the French text was dictated by the requirement to conform to this typographical detail, and not by semantic reasons.

Other cases of subtraction occurred in connection with paired synonyms, as

26. Eugene A. Nida, op. cit.

27. J.-P. Vinay and J. Darbelnet, op. cit.

Vol. $13-N^{\circ} 1$
Mars 1968 
in $« \ldots$ his hand is either wet or clammy ...», «présente une main moite ...» where French «moite» is sufficient to describe the state of a part of the body which is either soft and sticky or cold and moist. All paired synonyms were not treated in this manner, however. In one of the follow-up questions (Do you want to kill yourself or commit suicide?), both synonyms were retained in French after it was suggested that, in the minds of some patients, «to commit suicide 》 ( vous suicider 》) might refer to unsuccessful attempts while «to kill yourself» (《vous tuer») would evoke the real thing (a point not yet proven); in this case, the conjunction «ou» (or) was omitted in French since, in this language, it does not have the meaning of « in other words » but only of « otherwise».

An example of alteration is found in the question preceding the section on moods. In English, the patient is asked «What problems or difficulties do you have now? » in order to incite him to talk about his condition; the French equivalent in a similar situation is "Qu'est-ce qui ne va pas maintenant? " a formulation very different from the original, albeit with the same intent.

Translation techniques operating at the unit level have been organized and classified by Vinay and Darbelnet ${ }^{28}$ according to the degree to which the target expression deviates from the source expression. In increasing order of deviation, we find borrowing (emprunt), copying (calque), translating literally (traduction littérale), transposing (transposition), modulating (modulation), replacement (équivalence) and adjustment (adaptation).

Borrowing, that is bringing a source language word unchanged into the target text, is justified when introducing new concepts for which no word or suitable expression exists in the target language. We have already seen that English psychiatric usage borrowed French déjà $v u$ to describe a certain morbid state. Similarly «insight » seems to have been adopted by French psychiatric usage and was left unchanged in our translation. Other than that no borrowing was required since all questions and items were written in non technical language and since the few technical terms occurring belong to standard psychiatric terminology.

Copying refers to the practice of borrowing syntagmatic groups and translating each constituent element independently and without regard for target languages rules. An example of improper copying is « patient ambulant» instead of «malade sur pied » to translate «ambulatory patient» (French ambulant means without a known domicile, and patient is restricted to surgery patients ${ }^{29}$ ). Copying is justified when introducing new foreign concepts for which a better name cannot be found in the target language or when, for some reason, strict adherence to original terminology is deemed necessary. An example of copying occurs in the case of "to kill yourself or commit suicide», where both terms of a pair of synonyms are translated for fear there might be a special private meaning ascribed to each member of the pair by certain patients and this distinction would be lost if the usual practice of reducing the English pair to one word in French were followed.

Literal translation is the easiest and simplest form of translation, it occurs

28. J.-P. Vinay and J. Darbelnet, op. cit.

29. Glossaire des termes médico-hospitaliers, Montréal, Laboratoires Ayerst, 1966. 
whenever word by word replacement is possible without breaking rules in the target language; this, however, is quite rare unless the two languages are very closely related. Literal translation occurs once in the schedule: «How is your memory?», "Comment est votre mémoire?». Near literal translation is often possible, however, and occurs a number of times throughout the MSS, e.g., «Do you think you are sick? », «Croyez-vous que vous êtes malade?».

Transposing refers to replacing items from one grammatical class with those of another without changing the meaning of the utterance, e.g., "How old are you ?», "Quel âge avez-vous?»; « ... keeps feeling afraid ...», « ... a toujours peur ... $» ; \ll$... he feels hurt or overwhelmed when criticized $», \ll$... la critique le blesse ou l'accable».

Modulating is necessary when literal translation or transposing would produce a grammatically correct but semantically inaccurate (or meaningless) translation. It is similar to transposing, but on a different plane since it involves primarily meaning. "Says he ... feels dead》 thus becomes «Dit ... qu'il n'existe plus» (says he no longer exists) because «se sentir mort» (in literal translation) describes a state of excessive fatigue but not an absence of feeling. The phrase «peers and strangers» is translated by «les personnes autres que ses amis, sa famille, ses supérieurs » (persons other than friends, family or people in position of authority) because differences in psycho-social stratification would distort the original meaning. In American usage, «family »efers to a restricted biological unit consisting of father, mother and child (or children); "friends» refers to anyone not positively identified as family or stranger; «strangers » refers to persons one does not know; and «peers » defines a group of persons in some way equal to oneself, i.e., in age, rank, fortune, etc. In French usage, «famille» describes both the restricted biological unit and a larger unit involving all known relatives such as grandparents, grandchildren, aunts, uncles, nephews, nieces and cousins (worth noting is the fact that the one word «parents» refers either to " father and mother» or to relatives in general); «amis» is reserved, at least in France, to very close intimate acquaintances and this title is not easily granted; in French-Canada the term is used more freely than in France, but not quite so loosely as in the United States: «étrangers » applies to anyone who is neither a member of the family nor a friend; in contrast to American usage, "étrangers » may refer to someone known to the speaker, as when parents remind children to watch their table manners before «les étrangers» (actually dinner guests); «égaux» is used to designate persons who are equals in some very specific manner, such as members of a hierarchical organization occupying the same level, «pareils» is more comprehensive, including persons of similar age, character, talent, etc., and emphasizes similarity rather than equality, "pairs» is rare and used only in speaking of the individual's relations to the State. Had the MSS been prepared in French originally, the order of the questions under consideration would no doubt have been the reverse of what it is now: beginning with "famille * and «amis» the series would have ended with «étrangers» acting as the catch-all category. In translating it was not possible to change the order of items because of the typographical organization of the accompanying scoring sheet (which remains the same regardless of language). 
Replacement involves more than a shift in grammatical category (transposing) or semantical approach (modulating), requiring an original expression in the target text to be put in place of the source text expression. The translation of greetings, proverbs and other frozen forms almost always entails replacement. One question requires the subject to comment on his «sense of humor». This is an idiomatic expression referring to a disposition which includes a penchant for mirth, a sense of the incongruous, the ability to laugh at oneself and a sympathetic attitude toward human foibles; it is frequently used in English either in conversation or in writing. In French, the expression used with comparable frequency would be «esprit» (wit), but wit is more intellectual than humor, it is sometimes unkind, always keen, and consists of darting, flashing responses; comparable in terms of meaning would be «humour », but this is reserved for British or, at least, AngloSaxon humor, or else it is used in speaking of black humor which has overtones of cruelty, bitterness and despair. Clearly this is not the intended meaning. By studying the co-text, we see that the interviewer is really trying to find out whether the patient is still able to smile when asked to do so, and to enjoy a joke. An adequate replacement is «Avez-vous conservé votre bonne humeur? Est-ce que les plaisanteries vous amusent encore?».

Adjustment proper is a final resort in translation when an object, situation or event mentioned in the source text is unknown or inexistant in the target culture; it may take the form of an explanation, either inserted directly into the text or added in a footnote, or it may require a substitution, depending on the circumstances, the nature and relative importance of the item under consideration. No case of adjustment proper occurs in the schedule or in the inventory, probably because all the behavior referred to is basic and common to all cultures; but an example involving occupational categories in the accompanying Manual of Instructions was replaced, both for the sake of brevity and because the situation is less frequent in France than in the US: «Operates a presser in a dry cleaning store » becomes «Dessert les tables dans un restaurant» rather than «Fait fonctionner une machine à repasser dans une entreprise de nettoyage à sec».

IRÈNE V. SPILKA 